\title{
Maternal Mortality among African American Women in the State of Georgia, Causes, Policy, and Ethical Considerations
}

\author{
Zahra Shahin, $\mathrm{MPH}^{1}$, Isabella Hardwick, $\mathrm{MPH}^{1}$, Nancy Jeffery, MPH, RD, $\mathrm{LD}^{1}$, JaLisa Jordan, $\mathrm{MPH}^{1}$, and William A. Mase, \\ $\mathrm{DrPH}, \mathrm{MPH}, \mathrm{MA}^{1}$ \\ ${ }^{1}$ Jiann-Ping Hsu College of Public Health Department of Health Policy and Community Health, Georgia Southern University \\ Corresponding Author: William A. Mase • Faculty of Jiann-Ping Hsu College of Public Health, Department of Health Policy and Community Health, Georgia \\ Southern University • Statesboro, GA 30460 • Telephone: (912) 478-6984• Email: wmase@georgiasouthern.edu
}

\section{ABSTRACT}

Background: The U.S. is currently one of thirteen countries where maternal mortality rates (MMR) is worse now than it was fifteen years ago. Reducing maternal mortality is one of the significant challenges facing the health system in the United States, especially in the State of Georgia, which has one of the highest MMR in the nation. The purpose of this review is to explore the causes, policy, and ethical contextual factors contributing to increased maternal mortality rates among African American women in the State of Georgia. Also, identifying and addressing weaknesses and gaps that exist in the healthcare system and recommending policy implications to seek to reduce the MMR.

Methods: This study conducted a comprehensive literature review from the online database and also used data from CDC Wonder, OASIS Georgia, and Georgia Department of Public Health website to identify the primary antecedents of elevated MMR among African American women in the State of Georgia with specific attention to policy and ethical considerations.

Results: This review found factors that were related to causes of maternal death in the U.S. include socioeconomic status, communication between patient and healthcare provider, and maternal medical conditions and complications during pregnancy. In the State of Georgia, complications during pregnancy and cardiomyopathy were the leading cause of MMR, particularly among African American women in comparison with other races. However, inconsistency in reporting maternal death data was another issue that is discussed in this review.

Conclusions: Policies that incorporate ethical considerations need to be developed to benefit the family and society. Policymakers should seek to develop targeted policies in support of specific vulnerable populations through improving maternal screening, health promotion, behavior uptake, and effective case management.

Keywords: Georgia maternal mortality, African Americans and maternal mortality, prenatal care, obstetrics and maternal mortality, comorbidity, epidemiology, access to care.

\section{INTRODUCTION}

The Maternal Mortality Rate (MMR) refers to the number of maternal deaths per 100,000 live births (Maternal Mortality). The Centers for Disease Control and Prevention (CDC) defines maternal death as "the death of a woman while pregnant or within 42 days of termination of pregnancy, and it is irrespective from accidental or incidental causes" (First Data, 2020). The Maternal Mortality Rate (MMR) is broadly recognized as an indicator of overall population health, and reflects the health status of women within segments of the population. The MMR also serves as a proxy measure for the performance of a country's healthcare system (Sajedinejad et al., 2015). The MMR index is influenced by social and economic factors such as limited access to health services, health literacy status, lack of access to quality emergency obstetric and delivery care, and household income. Complications during pregnancy and childbirth are also other factors that increase MMR. However, improvements in health literacy, infrastructure, cultural change, and implementing interventions at each stage during pregnancy and childbirth can reduce maternal mortality outcomes (Black et al., 2016; $\&$ MacDorman et al., 2017).

Despite maternal health promotion technology advancement over the past decade, the MMR has continued to increase in the United States. A recent study in the U.S. illustrated that the estimated MMR from 2000-2014 increased from 18.8\% to $23.8 \%$ (MacDorman et al., 2016). According to 
America's Health Rankings United Health Foundation, the state of Georgia has one of the highest MMR in the nation (Explore, 2018). Also, in the state of Georgia, African American women are three times more likely to die from complications associated with pregnancy and childbirth compared to other races (GDPH, 2019). Notably, many studies have indicated that maternal mortality is significantly higher among African Americans compared to white women (MacDorman et al., 2016; MacDorman et al., 2017; \& Zhang et al., 2013). Information regarding the causes of maternal deaths is obtained from death certificates. Previously, in 2003 there was a revision to the International Classification of Disease (ICD-10) which included the addition of the pregnancy checkbox on the U.S. standard certificate of death that is used to clarify deaths in connection to pregnancy, childbirth, and the puerperium. However, the state of Georgia adopted the revision in 2008 (MacDorman et al., 2016).

The objective of this review is to present a comprehensive understanding of the causes of maternal death, particularly among African Americans in the U.S. with specific attention to the State of Georgia, and explore policies, and ethical contextual factors contributing to elevated maternal mortality rates specifically among such populations in the State of Georgia. Recommendations regarding ethical consideration and policy implications to reduce MMR are provided.

\section{METHODS}

This study used data from CDC's Wide-ranging Online Data for Epidemiologic Research (WONDER), Georgia Department of Public Health (GDPH) website, and online Analytical Statistical Information System (OASIS), and conducted a comprehensive literature review using peer reviewed published articles from electronic databases on the Georgia Southern University Libraries website i.e., PubMed, ScienceDirect, and other resources. The process of inclusion and exclusion of studies were based on a title review to find relevant studies and then followed by abstract reviews to further eliminate irrelevant articles. To obtain information regarding the causes of maternal death, this review included studies that were conducted in the United States; published between 2010 and 2019; online availability; medical and nonmedical factors associated with maternal death in the U.S. with specific attention to the State of Georgia, particularly among African Americans; also included published articles regarding policies, and ethical issues pertaining to maternal mortality rates in the U.S. This study excluded articles that were conducted outside the U.S.; and topics of pregnancy that were not related to maternal deaths. The results from the literature review were analyzed and synthesized to identify primary antecedents of elevated MMR among this target population in relation to causes, policies, and ethics. The findings were categorized into related topics that allowed for qualitative analysis to be applied and conducted meaningful interpretations. Through this process, main themes emerged and were categorized into recommendations that are discussed.

\section{RESULTS}

This review analyzed maternal death issues from different perspectives including socioeconomic factors, communication between patient and healthcare providers, maternal medical conditions and complications during pregnancy, also MMR data from sources such as CDC Wonder, AOSIS Georgia, Georgia Health Department and the revision of ICD-10 in the death certificate. In the following thematic sections a narrative summary of findings is provided.

\section{Socioeconomic Factors}

Socioeconomic status (SES) was found to be associated with maternal morbidity and mortality, especially among African American women. Women of low SES often suffer from poor nutrition, lack of medical care, social isolation, stress, (Blumenshine et al., 2010 \& Braveman et al., 2013), and have ineffective communication and weak interaction with care providers (Dahlem et al., 2015; Lori et al., 2011; \& Prather et al., 2018).

\section{Communication Factors}

Several studies claimed that ineffective patient-provider communication was one of the critical factors in delaying prenatal care among pregnant women particularly multiparous women in the State of Georgia (Meyer et al., 2016; \& Pacagnella et al., 2014). Miscommunication sometimes leads to a missed or late diagnosis that sometimes goes untreated throughout the pregnancy (Dahlem et al., 2015; Lori et al., 2017; \& Prather et al., 2018).

\section{Medical Condition Factors}

Researchers identified the leading causes of maternal death among women in the U.S. as cardiac disease, sepsis, hemorrhage, venous thromboembolism (VTE), hypertensive disorders of pregnancy, amniotic fluid embolism, peripartum cardiomyopathy, and complications during pregnancy (Afana et al., 2016; Fong et al., 2013; Kao et al., 2013; \& Sebillotte et al., 2010). Factors including gestational hypertension, gestational diabetes, preexisting conditions such as obesity, and cardiovascular disease (Edmonds et al., 2013; Singh et al., 2018; \& Xiang et al., 2011), age $\geq 45$ (Carolan, 2013), and anesthesia (Abir \& Mhyre, 2017) were identified as the causes of complications during pregnancy. This review also found that African American women have significantly higher rates of severe maternal morbidity (Howell, 2018) and are more likely to experience preeclampsia, placenta previa, preterm birth, vaginal bleeding, premature rupture of membranes, and 
cesarean delivery when compared to other ethnic groups (Braveman et al., 2011, \& Xiang et al., 2011).

\section{MMR Data}

While different factors were suggested as causes of maternal death, based on the information obtained from the Centers for Disease Control and Prevention (CDC) and the Georgia Department of Public Health (GDPH), complication during pregnancy (CDC Wonder, 2018) and cardiomyopathy (CDC Wonder, 2018; GDPH, 2017) are identified as the leading causes of MMR in the State of Georgia. Aggregate data from GDPH 2012-2014 showed that 16\% of pregnancy-related deaths were due to cardiomyopathy, $13 \%$ cardiovascular diseases and hemorrhage, and 10\% were due to embolism, preeclampsia, and eclampsia. Preeclampsia if misdiagnosed can lead to eclampsia (GDPH, 2019).

\section{Revision of ICD-10}

There are still challenges about the identification of maternal deaths when a recent or current pregnancy is unrecognized at the time of death. It is unclear if the rising number of reported maternal death cases in the U.S. and specifically Georgia is impacted by the revision of ICD-10, given the state of Georgia adopted it in 2008 (MacDorman et al., 2016). For states like Georgia, before the ICD-10 revision, if a woman presented and ended up dying due to acute renal failure, regardless of this being a complication to a recent or current pregnancy, it was coded as death due to acute renal failure. The changes in the ICD code make it possible to code for both maternal status and a condition that may not necessarily be pregnancy-related (Haelle, 2016). For example, in a recent study, the researchers found that when they reviewed 4,000,240 live births in the US in 1995 (pre-ICD-10 codes), maternal deaths were 302, which translated to a ratio of 7.55 deaths per 100,000 live births that year. When this compared to 1999 maternal mortality ratios increased to 9.88 per 100,000 births in 1999 , and 21.5 per 100,000 births in 2014 , making the 2014 ratio estimate nearly three times greater than the ratio two decades earlier (RR, 2.84; 95\% confidence interval [CI], 2.49 - 3.24) (Haelle, 2016).

\section{DISCUSSION}

Health inequality plays a significant role in maternal mortality and morbidity, particularly among African Americans, despite the efforts made to eliminate inequality and disparity in the U.S. healthcare system (Dahlem et al., 2015; Lori et al., 2011; Prather et al., 2018; Xiang et al., 2011; \& Zhang et al., 2013). Other factors such as poor interaction and ineffective patient-provider communication are also significant issues that should be considered. Ineffective communication and interaction between pregnant women and healthcare providers has a negative impact on maternal outcomes especially in cases with the pre-existing conditions (Chang et al., 2018; Madula et al., 2018; \& Nair et al., 2014), and can create obstacles to obtaining adequate prenatal care. Prenatal care provides women access to health education, nutritional support, preventative care services, and social services to ensure healthy outcomes for both the mother and the child (Dahlem et al., 2015).

Establishing a rapport between patients and providers is essential to assuring quality pre and postnatal care outcomes particularly among African-American women. Ineffective communication and interaction between pregnant women and healthcare providers have impacted pregnancy outcomes in the State of Georgia. This problem could result in delayed diagnosis or misdiagnosis of complications during pregnancy. As a result, it affects timely reporting or referring of high-risk cases to specialists or higher-level care providers to take required actions (Haddrill et al., 2014; \& Pacagnella et al., 2014). In addition, delaying prenatal care causes gaps in the information system, and more importantly, in cases of preexisting conditions, or complications, mothers do not get the care they need during pregnancy. There is increasing evidence that pregnant women with preexisting conditions are more susceptible to complications during pregnancy and childbirth (D'Oria 2016; \& Planter et al, 2016).

Moreover, scarcity in collecting meaningful data in the information system leads to missing high-risk cases which sometimes end up with adverse pregnancy outcomes (Bongaarts, 2016; \& Brown et al., 2013). Without enough data regarding maternal medical history in the information system, Maternal Mortality Review Committees (MMRCs) cannot analyze and determine the underlying causes of maternal death, and that is pivotal in developing policies, decision making, and reducing or eliminating the causes of maternal morbidity and mortality (Report, 2017).

Currently, six regional perinatal centers in the State of Georgia provide care for high-risk pregnancy cases (Perinatal Health, 2018) (see Figure 1). However, with the highest rates of maternal deaths related to complications, it can be assumed that these centers are located near larger cities that create access barriers if a woman experiences a high-risk pregnancy and is not close to one of the regional perinatal centers. 
Figure 1

Georgia by Perinatal Regions

\section{Georgia by Perinatal Regions}
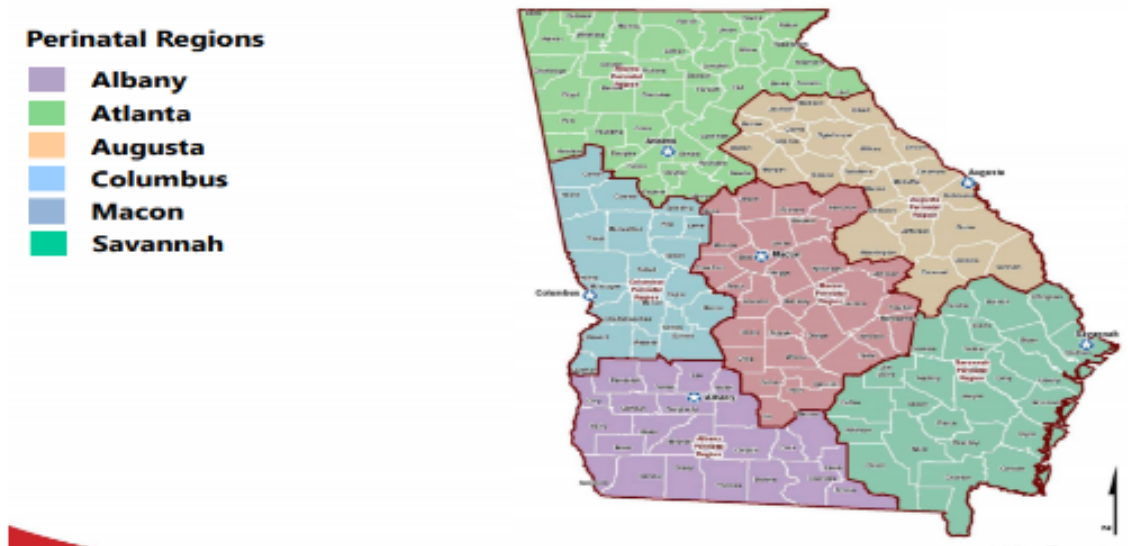

Figure I, Regioual Perinatal System - Georgia State Senate www.senate.ga.gov > cominittocs > Documents > DPHS.

Another assumption is that women with high-risk pregnancies may have limited or no access to perinatal specialists to diagnose the warning signs and symptoms of complications during pregnancy to provide the necessary care and prevent adverse pregnancy outcomes (Counseling for Maternal, 2013).

This review also identified inconsistencies regarding reported MMR data by the CDC Wonder and Online
Analytical Statistical Information System (OASIS) Georgia. For instance, in 2017, CDC Wonder reported 74 maternal deaths for the State of Georgia, but OASIS Georgia reported 48 maternal deaths for the same year. Inconsistencies were more noticeable after the year 2010 (see Figure 2) (CDC Wonder, 2018; \& OASIS, 2018).

Figure 2

Comparing maternal mortality for the state of Georgia

Comparing Maternal Death Reports for the State of Geargia

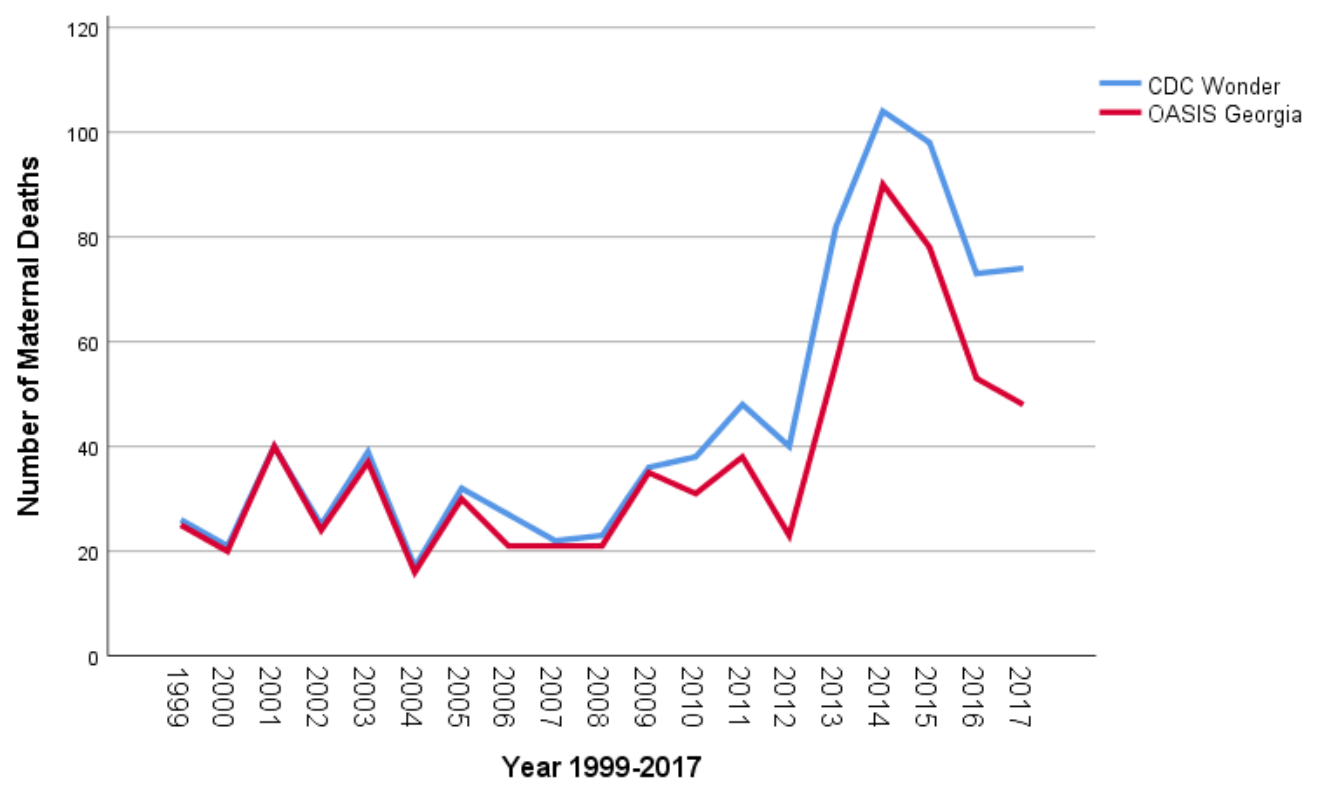


Therefore, it is crucial that the Georgia Department of Public Health and CDC Wonder check to ensure the accuracy and reliability of maternal death data before publishing it.

A further issue was observed in collecting data regarding death certificate and ICD-10 coding. Researchers found that the checkbox in the death certificate that questions about the pregnancy, from time to time, inadvertently checked; even though the mother's death did not have any relevance to pregnancy. They discovered that "a 1\% false positive report increased MMR by $26 \%$ for women aged $<40$, and more than tripled for women aged 40-54" (MacDorman et al., 2017). However, the US vital statistics system and the Georgia Department of Public Health need to carefully investigate such issues in the State of Georgia and take all necessary measures to ensure the accuracy of recorded maternal death data.

\section{Limitations}

There are several limitations to our study that need to be addressed. Even though the focus of our research was on maternal death among African American women in the State of Georgia, we could not find enough studies that solely focused on such an issue. We also did not study other factors that could relate to the causes of maternal death such as age and multi pregnancy. We used data from the CDC wonder, GDPH website, and OASIS Georgia to find the leading causes of maternal mortality and measure trends of MMR in different years in the State of Georgia, and since the State of Georgia adopted ICD-10 in 2008 the accuracy of comparison of MMR in different years cannot be determined.

\section{Rights Approach to Ethical Decision-making}

This review examined the causes associated with rising MMR rates in the State of Georgia. Given that the issues related to MMR are complex, we believe a starting point is to apply the rights approach. The focus of the rights approach is on respect for human dignity; it is the ability to choose how we live our lives, and have a moral right to respect our choices as free, equal, and rational people, and a moral duty to respect others in the same way.

In the case of Georgia statistics, we believe if quality healthcare systems were able to provide quality care, using a referral system from the community level, maternal mortality rates would decrease (Hawkins et al., 2005) and there would be a lack of equivocality among African American women and health care providers. The rights approach emphasizes that services should be available, accessible, acceptable and of the highest quality. This review highlighted the importance of a rights-based approach to access to care for Georgians. This would spotlight non-discrimination and equity, and it would draw attention to our target population who are not currently using the services, but also to the underlying social and cultural factors that perpetuate the inability to do so (Hawkins et al., 2005).

Applying a rights-based approach to maternal mortality can increase the focus on interventions that address the underlying injustices that prevent women from accessing life-saving services they need. It also calls to question the ethics of charging for prenatal and obstetric care. The State of Georgia also needs to prioritize maternal health and educate healthcare providers on knowledge, experience, implicit bias, cultural competence, and communication. Furthermore, educating pregnant African American women in philosophy, beliefs, health behaviors, self-efficacy, and social support can contribute to improved maternal outcomes and health services. According to Hawkins et al., in order for this to be successful, it needs to be done in parallel with local, state and national policies that help women in particular, and to hold government and service providers accountable (2005). Hawkins et al. (2005) stated that when employing a rights-based approach, it can contribute to assessing the reasons behind delays in seeking, accessing and receiving care. A rights-based approach would impel governments and their funding partners, as well as communities to address the problem of poor referral systems (Hawkins et al., 2005).

Finally, the rights-based approach would ensure that African American women in the State of Georgia have access to expanded health care options including expanded Medicaid without causing a financial burden, or increasing vulnerability. However, while the rights-based approach is imperative to the promotion of desired changes, it presents challenges that need to be carefully considered by local and state governments when prioritizing their activities and resources.

In summary, women must have access to high quality and standardized healthcare services throughout their pregnancy (pre and postnatal care). Stakeholders, including policymakers, public health officials, and healthcare providers are accountable for reducing maternal mortality and have the responsibility to prevent maternal deaths from occurring by ensuring availability, accessibility, and affordability of resources regarding perinatal care (Thomas et al., 2018).

\section{Policy Recommendations and Future Implications}

The following recommendations are suggested based on the information obtained from resources used in this review to improve maternal care and address issues surrounding the 
causes of maternal mortality in the State of Georgia.In general, existing policy and regulations regarding reproductive and pregnancy care should be strengthened and enforced to provide all women universal health coverage without restrictions to access to health services and provide free access to contraception to prevent unwanted or too-early pregnancies (Moaddab, et al., 2016).

Healthcare systems should mandate care providers to carefully screen all women during and after pregnancy regarding cardiac disease, blood pressure (in terms of preeclampsia and eclampsia), and thromboembolism since such risk factors were the most causes of maternal death in the State of Georgia, and examine the history of previous pregnancies in case of the incidence of placenta adhesion disorder to take necessary measures, and improve perinatal care outcomes (Henderson et al., 2017). Healthcare systems should also implement and promote pre-pregnancy counseling to detect high-risk cases and provide managed care (Prepregnancy Counseling, 2019).

To assure strides are made towards improving maternal care, public health and healthcare systems should train and recruit healthcare professionals such as midwives in the system; obligate them to monitor and follow up high-risk pregnancy cases with pre-existing conditions and record their actions in detail. Encourage collaboration among private clinics, hospitals, healthcare systems, and public health departments (Counseling for Maternal, 2013).

In addition, healthcare providers should have continuing education programs regarding emergency guidelines and protocols, leading causes of maternal death, and high-risk pregnancies, particularly among African American women (Lu et al., 2015). At the same time, healthcare professionals need to educate and raise awareness about the importance of perinatal care, high-risk pregnancy, complications, warning signs and symptoms during pre and post pregnancy to all women specifically among women in reproductive age (Lu et al., 2015). Plus, inform pregnant women about the existence of the six Regional Perinatal Centers in the State of Georgia, and refer high-risk cases for additional screening and assessment to such centers (Regional Perinatal Centers, 2018).

Further, healthcare systems should offer training sessions in communication skills and encourage healthcare professionals to participate in the program (Dahlem et al., 2015) since poor communication was a significant contributing factor in delaying prenatal care and resulted in late diagnosis or misdiagnosis of complications during pregnancy (Haddrill et al., 2014; \& Pacagnella et al., 2014). On the other hand, state and local governments should invest in and benefit from the recent advancement in technology created and designed by "Kognito," a health simulation company. This new online stimulation program uses a virtual human to have an interactive role-play with people. This program provides health care professionals with a framework on how to navigate difficult health conversations, and improve individuals' social, emotional, and physical health in ways that enable patients to feel more comfortable talking about their health situations. There is also a designed program for patients that lets them ask questions and get answers by a fully-articulated and emotionally responsive virtual human. In this way, patients feel more comfortable and less judged to ask questions and lead the conversation (Pan \& Hamilton, 2018).

Public health and healthcare systems also need to ensure the consistency and reliability of data that are collected. This is possible by improving the information system and conducting vigilant monitoring and proper surveillance of the performance of healthcare providers (Braithwaite et al., 2017; \& Naseriasl et al., 2015). For this purpose, it is essential to create a standardized electronic health record for universal collection and compilation of healthcare data. By doing this, communication and coordination among different stakeholders including specialists, other care providers (Chang et al., 2018; \& Naseriasl et al., 2015), and pregnant women can be enhanced (Madula et al., 2018); also, high-risk cases can be detected promptly (Rowe et al., 2018). Most importantly, public health departments and healthcare systems can use the information system more efficiently for investigating and targeting the root causes of maternal death, identifying high priority policies, and determining the effective strategic planning that improves maternal care outcomes.

Likewise, the state and local government should obligate the Maternal Mortality Review Committee to carefully analyze the root cause of death for each case. For this purpose, public health departments and healthcare systems should generate a standardized form that requires the committee to provide detailed information regarding the exact cause of maternal mortality. Such measures allow both public health and healthcare systems to identify avoidable factors and develop required policy changes to improve maternal care outcomes. Policy makers within the US vital statistics system should examine the accuracy of death certificate reports and scrutinize the exact causes of deaths. Finally, the public health department should compare maternal death certificates with results of the Maternal Mortality Review Committee reports periodically to ensure the accuracy of data.

\section{CONCLUSIONS}

Even though the Georgia Department of Public Health and CDC Wonder need to carefully monitor maternal death data and check to ensure the accuracy of collected information, the State of Georgia still has the worst maternal health outcomes among African American women when compared to other states in the U.S., despite having resources and advances in medical technology (Amankwaa et al., 2018). 
Health disparity and social inequality appear to be the major causes of maternal mortality and morbidity, particularly among African Americans. Therefore, policies should identify and eliminate such inequalities and disparities in the healthcare system, and provide all women access to equal and standardized healthcare regardless of their socioeconomic status, race, cultural background, and ethnicity (Cook, 2013). In addition, maternal care needs to be performed by health professionals and skilled individuals such as educated midwives. The outcomes of such policies and intervention programs may improve maternal care nationwide particularly among low social income groups including African American women (Daniel et al., 2018). Maternal mortality can also be reduced through effective maternal screening, health promotion, health behavior changes and effective case management underpinned by the rights approach that emphasizes respect for human dignity.

\section{References}

Abir, G., \& Mhyre, J. (2017). 9: Maternal mortality and the role of the obstetric anesthesiologist. Best Practice \& Research Clinical Anaesthesiology, 31, 91-105. doi:10.1016/j.bpa.2017.01.005

ACOG Committee Opinion No. 762 Summary: Prepregnancy Counseling. (2019). Obstetrics \& Gynecology(1), 228. doi:10.1097/AOG.0000000000003014

Afana, M., Brinjikji, W., Kao, D., Jackson, E., Maddox, T. M., Childers, D., . . . Davis, M. B. (2016). Characteristics and In-Hospital Outcomes of Peripartum Cardiomyopathy Diagnosed During Delivery in the United States From the Nationwide Inpatient Sample (NIS) Database. Journal Of Cardiac Failure, 22(7), 512-519. doi:10.1016/j.cardfail.2016.02.008

Amankwaa, L. C., Records, K., Kenner, C., Roux, G., Stone, S. E., \& Walker, D. S. (2018). African-American mothers' persistent excessive maternal death rates. Nursing Outlook, 66(3), 316-318. doi:10.1016/j.outlook.2018.03.006

Bateman, B. T. (2018). Review article: What's New in Obstetric Anesthesia: a focus on maternal morbidity and mortality. International Journal of Obstetric Anesthesia. doi:10.1016/j.ijoa.2018.09.004

Bibbins-Domingo, K., Grossman, D. C., Curry, S. J., Barry, M. J., Davidson, K. W., Doubeni, C. A., Tseng, C. W. (2017). Screening for Preeclampsia: US Preventive Services Task Force Recommendation Statement. Jama, 317(16), 1661-1667. doi:10.1001/jama.2017.3439

Black, R. E., Levin, C., Walker, N., Chou, D., Liu, L., \& Temmerman, M. (2016). Review: Reproductive, maternal, newborn, and child health: key messages from Disease Control Priorities 3rd Edition. The Lancet, 388, 2811-2824. doi:10.1016/S0140-6736(16)00738-8

Blumenshine, P., Egerter, S., Barclay, C. J., Cubbin, C., \& Braveman, P. A. (2010). Socioeconomic Disparities in Adverse Birth Outcomes:A Systematic Review(3), 263. Retrievedfrom https://libez.lib.georgiasouthern.edu/login?url=https://search.ebs cohost.com/login.aspx?direct $=$ true $\& d b=$ edsbl\&AN=RN2765151 60

Bohren, M. A., Vogel, J. P., Hunter, E. C., Lutsiv, O., Makh, S. K., Souza, J. P., Gülmezoglu, A. M. (2015). The Mistreatment of Women during Childbirth in Health Facilities Globally: A Mixed-Methods Systematic Review. PLoS Medicine, 12(6), 1-32. doi:10.1371/journal.pmed.1001847

Bongaarts, J. (2016). WHO, UNICEF, UNFPA, World Bank Group, and United Nations Population Division Trends in
Maternal Mortality: 1990 to 2015 Geneva: World Health Organization, 2015. Population and Development Review(4), 726. doi:10.1111/padr.12033

Braithwaite J, Hibbert P, Blakely B, Plumb J, Hannaford N, Long JC, Marks D. (2017). Health system frameworks and performance indicators in eight countries: A comparative international analysis. SAGE Open Medicine. doi: $10.1177 / 2050312116686516$

Braveman, P., \& Gruskin, S.Brown, H. L., Small, M., Taylor, Y. J., Chireau, M., \& Howard, D. L. (2011). Near Miss Maternal Mortality in a Multiethnic Population. Annals of Epidemiology, 21, 73-77. doi:10.1016/j.annepidem.2010.10.009

Braveman, P., \& Gruskin, S.Edmonds, J. K., Yehezkel, R., Liao, X., \& Moore Simas, T. A. (2013). Racial and ethnic differences in primary, unscheduled cesarean deliveries among low-risk primiparous women at an academic medical center: a retrospective cohort study. BMC Pregnancy And Childbirth, 13, 168-168. doi:10.1186/1471-2393-13-168

Brown, M. C., Best, K. E., Pearce, M. S., Waugh, J., Robson, S. C., \& Bell, R. (2013). Cardiovascular disease risk in women with pre-eclampsia: systematic review and meta-analysis. European Journal Of Epidemiology, 28(1), 1-19. doi:10.1007/s10654-013-9762-6

Carolan, M. (2013). Maternal age $\geq 45$ years and maternal and perinatal outcomes: a review of the evidence. Midwifery, 29(5), 479-489. doi:10.1016/j.midw.2012.04.001

CDC Wonder. (2018). Maternal Mortality Rates of Georgia Residents 1999-2017 by Age:https://wonder.cdc.gov/controller/saved/D77/D51F188

Central of Disease Control. Report from Maternal Mortality Review Committees - CDC Foundation. 2017. Available at: www.cdcfoundation.org/sites/default/files /upload /pdf/ MMRIAReport.pdf. Accessed September 11, 2018

Chang, Y.-S., Coxon, K., Portela, A. G., Furuta, M., \& Bick, D. (2018). Interventions to support effective communication between maternity care staff and women in labour: A mixed-methods systematic review. Midwifery., 59, 4-16. doi:10.1016/j.midw.2017.12.014

Cook, R. J. (2013). Human Rights and Maternal Health: Exploring the Effectiveness of the Alyne Decision. Journal of Law, Medicine \& Ethics, 41(1), 103-123. doi:10.1111/jlme.12008

Counseling for Maternal and Newborn Health Care A Handbook for Building Skills. (2013). Geneva: World Health Organization; ISBN-13: 978-92-4-154762-8

Daniel, H., Erickson, S. M., \& Bornstein, S. S. (2018). Women's Health Policy in the United States: An American College of Physicians Position Paper(12), 874. Retrieved from https://libez.lib. georgiasouthern.edu / login?url=https://search.ebscohost.com/login.aspx?direct=true\& $\mathrm{db}=$ edsbl\&AN=RN617275077

Dahlem, C. H. Y., Villarruel, A. M., \& Ronis, D. L. (2015). African American women and prenatal care: perceptions of patient-provider interaction. Western Journal Of Nursing Research, 37(2), 217-235. doi:10.1177/0193945914533747

D'Oria, R., Myers, J., \& Logsdon, M. C. (2016). Strategies to Reduce Maternal Mortality During the First Year After Birth. In (Vol. 45, pp. 885-893): Journal of Obstetric, Gynecologic \& Neonatal Nursing.

Edmonds, J. K., Yehezkel, R., Liao, X., \& Moore Simas, T. A. (2013). Racial and ethnic differences in primary, unscheduled cesarean deliveries among low-risk primiparous women at an academic medical center: a retrospective cohort study. BMC Pregnancy And Childbirth, 13, 168-168. doi:10.1186/1471-2393-13-168 
Explore Maternal Mortality in the United States | 2018 Health of https://www.americashealthrankings.org/explore/health-of-wom en-and-children/meas

First Data Released on Maternal Mortality in Over a Decade. (2020). www. cdc. gov nchs press_releases > MMR

Fong, A., Chau, C. T., Pan, D., \& Ogunyemi, D. A. (2013a). Clinical morbidities, trends, and demographics of eclampsia: a population-based study. American Journal Of Obstetrics And Gynecology, 209(3), 229.e221-227.

doi:10.1016/j.ajog.2013.05.050

Georgia DPH.( 2019).

https://ph.georgia.gov/sites/dph.georgia.gov/files /MCH/MMR/

Maternal MortalityFactSheet.FINAL2014data.pdf

Haelle, T. Maternal Mortality Increase Explained by Coding Changes? Medscape 2016.

Haddrill, R., Jones, G. L., Mitchell, C. A., \& Anumba, D. O. C. (2014). Understanding delayed access to antenatal care: a qualitative interview study. BMC Pregnancy \& Childbirth, 14(1), 1-14. doi:10.1186/1471-2393-14-207

Hameed, A. B., Lawton, E. S., McCain, C. L., Morton, C. H., Mitchell, C., Main, E. K., \& Foster, E. (2015).

Pregnancy-related cardiovascular deaths in California: beyond peripartum cardiomyopathy. Am J Obstet Gynecol, 213(3), 379.e371-310. doi:10.1016/j.ajog.2015.05.008

Hawkins K., Newman K., Thomas D. Cindy Carlson (2005). Developing a Human Rights-Based Approach to Addressing Maternal. DFID Health Resource Centre.

https://webarchive.nationalarchives.gov .uk/2008 1024000458. maternal-desk.pdf

Henderson, J. T., Thompson, J. H., Burda, B. U., \& Cantor, A. (2017). Preeclampsia screening: evidence report and systematic review for the US Preventive Services Task Force. JAMA, The Journal of the American Medical Association(16), 1668.

Howell E A. (2019). Reducing Disparities in Severe Maternal Morbidity and Mortality Clin Obstet Gynecol. Clin Obstet Gynecol. 61(2): 387-399. doi:

10.1097/GRF.0000000000000349

Kao, D. P., Hsich, E., \& Lindenfeld, J. (2013). Characteristics, adverse events, and racial differences among delivering mothers with peripartum cardiomyopathy. JACC. Heart Failure, 1(5), 409-416.

Lo, J. O., Mission, J. F., \& Caughey, A. B. (2013). Hypertensive disease of pregnancy and maternal mortality. Curr Opin Obstet Gynecol, 25(2), 124-132. doi:10.1097/GCO.0b013e32835e0ef5

Lori, J. R., Yi, C. H., \& Martyn, K. K. (2011). Provider characteristics desired by African American women in prenatal care. Journal Of Transcultural Nursing: Official Journal Of The Transcultural Nursing Society, 22(1), 71-76. doi:10.1177/1043659610387149

Lu, M., Highsmith, K., Cruz, D., \& Atrash, H. (2015). Putting the 'M' Back in the Maternal and Child Health Bureau: Reducing Maternal Mortality and Morbidity. Maternal \& Child Health Journal, 19(7), 1435. doi:10.1007/s10995-015-1665-6

MacDorman MF, Declercq E, Cabral H, Morton C. (2016). Is the United States Maternal Mortality Rate Increasing?

Disentangling trends from measurement issues Short title: U.S. Maternal Mortality Trends. Obstet Gynecol. Author manuscript; available in PMC 2016 Sep 1. Published in final edited form as: Obstet Gynecol. 2016 Sep; 128(3): 447-455. doi: 10.1097/ AOG.0000000000001556

MacDorman, M. F., Declercq, E., \& Thoma, M. E. (2017). Trends in Maternal Mortality by Sociodemographic Characteristics and Cause of Death in 27 States and the District of Columbia. Obstetrics \& Gynecology, 129(5), 811.

Madula, P., Kalembo, F. W., Yu, H., \& Kaminga, A. C. (2018). Healthcare provider-patient communication: a qualitative study of women's perceptions during childbirth. Reproductive Health, 15(1), 135-135. doi:10.1186/s12978-018-0580-x

Manuck, T. A. (2017). Racial and ethnic differences in preterm birth: A complex, multifactorial problem. Semin Perinatol, 41(8), 511-518. doi:10.1053/j.semperi.2017.08.010

Meyer, E., Hennink, M., Rochat, R., Julian, Z., Pinto, M., Zertuche, A. D., Cota, P. (2016). Working Towards Safe Motherhood: Delays and Barriers to Prenatal Care for Women in Rural and Peri-Urban Areas of Georgia. Maternal And Child Health Journal, 20(7), 1358-1365. doi:10.1007/s10995-016-1997-x

Moaddab, A., Dildy, G. A., Brown, H. L., Bateni, Z. H., Belfort, M. A., Sangi-Haghpeykar, H., \& Clark, S. L. (2018). Health Care Disparity and Pregnancy-Related Mortality in the United States, 2005-2014. Obstetrics \& Gynecology, 131(4), 707-712. doi:10.1097/AOG.0000000000002534

Nair, M., Yoshida, S., Lambrechts, T., Boschi-Pinto, C., Bose, K., Mason, E. M., \& Mathai, M. (2014). Facilitators and barriers to quality of care in maternal, newborn and child health: a global situational analysis through metareview. BMJ Open, 4(5), e004749-e004749. doi:10.1136/bmjopen-2013-004749

Naseriasl, M., Adham, D., \& Janati, A. (2015). E-referral Solutions: Successful Experiences, Key Features and Challenges- a Systematic Review. Materia Socio-Medica, 27(3), 195-199. doi:10.5455/msm.2015.27.195-199

Neggers, Y. H. (2016). Trends in maternal mortality in the United States. Reproductive Toxicology, 64, 72-76. doi:10.1016/j.reprotox.2016.04.001

Online Analytical Statistical Information System Georgia Department https://oasis.state.ga.us/

Pacagnella, R. C., Cecatti, J. G., Parpinelli, M. A., Sousa, M. H., Haddad, S. M., Costa, M. L., . . . Pattinson, R. C. (2014). Delays in receiving obstetric care and poor maternal outcomes: results from a national multicentre cross-sectional study. BMC Pregnancy And Childbirth, 14, 159-159. doi:10.1186/1471-2393-14-159

Pan, X., \& Hamilton, A. F. d. C. (2018). Why and how to use virtual reality to study human social interaction: The challenges of exploring a new research landscape. British Journal of Psychology(3), 395.

Perinatal Health. (2018).Georgia Department of Public Health https://dph.georgia.gov/perinatal-health

Platner, M., Loucks, T. L., Lindsay, M. K., \& Ellis, J. E. (2016). Pregnancy-Associated Deaths in Rural, Nonrural, and Metropolitan Areas of Georgia. Obstet Gynecol, 128(1), 113-120. doi:10.1097/AOG.0000000000001456

Prather, C., Fuller, T. R., Jeffries, W. L. t., Marshall, K. J., Howell, A. V., Belyue-Umole, A., \& King, W. (2018). Racism, African American Women, and Their Sexual and Reproductive Health: A Review of Historical and Contemporary Evidence and Implications for Health Equity. Health Equity, 2(1), 249-259. doi:10.1089/heq.2017.0045

Prepregnancy counseling. (2019). Fertility and Sterility American Society for Reproductive Medicine, Birmingham, Alabama; and American College of Obstetricians and Gynecologists, Washington, D.C. vol. 111 no. 1 https://www.fertstert.org/article/S0015-0282(18)32252-0/pdf

Regional Perinatal Centers. (2018) | Georgia Department of Public Health. https://dph.georgia.gov/RPC. web

Report from Maternal Mortality Review Committees - CDC Foundation.

https://www.cdcfoundation.org/sites/default/files/files/MMRIAR eport.pdf

Rowe AK, Rowe SY, Peters DH, Holloway KA, Chalker J, Ross-Degnan D. (2018). Effectiveness of strategies to improve health-care provider practices in low-income andmiddle-income 
countries: a systematic review. Lancet Glob Health. 6(11):e1163-e1175. doi: 10.1016/ S2 214-109X(18)30398-X. Epub 2018 Oct 8.

Sajedinejad, S., Majdzadeh, R., Vedadhir, A., Tabatabaei, M. G., \& Mohammad, K. (2015). Maternal mortality: a cross-sectional study in global health. Globalization \& Health, 11(1), 1-13. doi:10.1186/s12992-015-0087-y

Sebillotte, C. G., Deligny, C., Hanf, M., Santiago, R., Chevallier, J. C., Voluménie, J. L., \& Arfi, S. (2010). Is African descent an independent risk factor of peripartum cardiomyopathy? International Journal Of Cardiology, 145(1), 93-94. doi:10.1016/j.ijcard.2009.05.042

Shahul, S., Tung, A., Minhaj, M., Nizamuddin, J., Wenger, J., Mahmood, E., Rana, S. (2015). Racial Disparities in Comorbidities, Complications, and Maternal and Fetal Outcomes in Women With Preeclampsia /eclampsia . Hypertens Pregnancy, 34(4), 506-515. doi:10.3109/10641955.2015. 109 0581

Singh, G. K., Siahpush, M., Liu, L., \& Allender, M. (2018). Racial/Ethnic, Nativity, and Sociodemographic Disparities in Maternal Hypertension in the United States, 2014-2015. International Journal Of Hypertension, 2018, 7897189-7897189. doi: $10.1155 / 2018 / 7897189$
Siri, M. J., Cork, D. L., \& National Research, C. (2009). Vital Statistics : Summary of a Workshop. Washington, D.C.: National Academies Press.

Thomas Wiswa, J., Dickson Ally, M., Gasto, F., \& Isabel, G. (2018). An account for barriers and strategies in fulfilling women's right to quality maternal health care: a qualitative study from rural Tanzania. BMC Pregnancy and Childbirth, Vol 18, Iss 1, Pp 1-10 (2018)(1), 1. doi:10.1186/s12884-018-1990-z

WHO Maternal mortality ratio (per 100000 live births). https://www.who.int/healthinfo/statistics/indmaternalmortality/e $\mathrm{n} /$

Xiang, A. H., Li, B. H., Black, M. H., Sacks, D. A., Buchanan, T. A., Jacobsen, S. J., \& Lawrence, J. M. (2011). Racial and ethnic disparities in diabetes risk after gestational diabetes mellitus. Diabetologia, 54(12), 3016-3021. doi:10.1007/s00125-011-2330-2

Zhang, S., Cardarelli, K., Shim, R., Ye, J., Booker, K., \& Rust, G. (2013). Racial Disparities in Economic and Clinical Outcomes of Pregnancy Among Medicaid Recipients. Maternal \& Child Health Journal, 17(8), 1518-1525. doi:10.1007/s10995-012-1162-0

(C) Zahra Shahin, Isabella Hardwick, Nancy Jeffery, JaLisa Jordan, and William A. Mase. Originally published in jGPHA (http://www.gapha.org/jgpha/) July 24, 2020. This is an open-access article distributed under the terms of the Creative Commons Attribution Non-Commercial No-Derivatives License (http://creativecommons.org/licenses/by/4.0/), which permits unrestricted use, distribution, and reproduction in any medium, provided the original work ("first published in the Journal of the Georgia Public Health Association...") is properly cited with original URL and bibliographic citation information. The complete bibliographic information, a link to the original publication on http://www.gapha.jgpha.org/, as well as this copyright and license information must be included. 